\title{
ENGAJAMENTO SOB O VIÉS DA LINGUÍSTICA SISTÊMICO- FUNCIONAL EM TEXTO MIDIÁTICO: ANÁLISE DE UM ARTIGO DE OPINIÃO DE MIRIAM LEITÃ̃
}

\author{
ENGAGEMENT UNDER THE BIAS OF SYSTEMIC-FUNCTIONAL \\ LINGUISTICS IN MEDIA TEXT: ANALYSIS OF AN OPINION \\ ARTICLE BY MIRIAM LEITÃO
}

\author{
Carolina Zeferino Pires (UFRGS) \\ carolinazeferinopires@gmail.com \\ Letícia Domanski (UFRGS) \\ ledomanski@gmail.com
}

\begin{abstract}
RESUMO: O presente artigo, fundamentado na Linguística Sistêmico-Funcional de Halliday (1985; 1994) e Halliday e Matthiessen (2014), aborda os recursos de posicionamento intersubjetivo em texto midiático, com base teórica voltada essencialmente para o Sistema de Avaliatividade da semântica do discurso (MARTIN; WHITE, 2005). O objetivo é reconhecer se a voz autoral é monoglóssica ou heteroglóssica com o intuito de compreender como são construídas as relações entre a autora e o seu público leitor. Para tanto, a análise, feita manualmente, concentra-se no subsistema de engajamento, com foco nas categorias monoglossia e heteroglossia e subcategorias de contração e expansão dialógicas. Os resultados revelaram um movimento de alternância entre monoglossia e heteroglossia ao longo do texto, revelando alta responsabilidade autoral, no primeiro caso, e uma abertura de canal comunicativo, no segundo, sem comprometer tal responsabilidade.
\end{abstract}

PALAVRAS-CHAVE: linguística sistêmico-funcional; avaliatividade; engajamento; heteroglossia.

ABSTRACT: This article, based on Systemic Functional Linguistics, developed by Halliday (1985, 1994) and Halliday and Matthiessen (2014), discusses the resources of an intersubjective positioning in media texts, with a theoretical basis focused essentially on the Appraisal System of discourse semantics (MARTIN; WHITE, 2005). It aims to recognize whether the authorial voice is monoglossic or heteroglossic in order to understand how the relationships between the author and their readership are built. Therefore, the analysis, carried out manually, centers around the engagement subsystem, focusing on the monoglossic and heteroglossic categories and subcategories of dialogic contraction and expansion. The results revealed an alternating movement between monogloss and heterogloss throughout the 
text, revealing high authorial responsibility, in the first case, and an opening of a communications channel, in the second, without compromising this responsibility.

KEYWORDS: Systemic Functional Linguistics; appraisal; engagement; heterogloss.

E outra coisa: nos meus livros, quero profundamente a comunicação profunda comigo e com o leitor. Aqui no jornal apenas falo com o leitor e agrada-me que ele fique agradado.

Clarice Lispector, A descoberta do mundo

\section{Introdução}

A reflexão da autora Clarice Lispector, em epígrafe, sobre a comunicação que se estabelece entre autor e leitor em crônicas jornalísticas nos leva a problematizar como e de que forma a preocupação com a recepção do que se escreve é decisiva no momento da escrita. Neste sentido, as vozes presentes em um texto estabelecem diferentes efeitos retóricos potenciais, afastando a premissa de que o jornalismo possa ser isento ou imparcial. Considerando que a escrita jornalística se apresenta como um espaço de negociação entre quem escreve e quem lê, ao dizer algo, o autor, assim como postulado por Lispector, preocupa-se em estabelecer laços de solidariedade com o leitor, que ocorrem por meio de potenciais de significado anuentes ou discordantes. Neste artigo, a Linguística Sistêmicofuncional (doravante LSF) é o aparato teórico-metodológico utilizado para caracterizar e discutir a heteroglossia e a monoglossia (MARTIN; WHITE, 2005) presentes em um texto midiático (Impeachment pelo passado e futuro, publicado na coluna de Miriam Leitão no jornal $O$ Globo, 24/01/2021). A LSF, postulada por Halliday (1985; 1994) e Halliday e Matthiessen (2014) é o ponto de partida dos pressupostos de Martin e White (2005) para estabelecer o sistema de Avaliatividade da língua e seu subsistema de engajamento. Tal subsistema é caracterizado e mobilizado, neste artigo, para compreender como os recursos linguísticos são utilizados em um artigo de opinião publicado no jornal O Globo em sua versão digital.

Assim, o presente artigo desenrola-se da seguinte forma: na seção 2 são apresentados os pressupostos teóricos da LSF pertinentes ao entendimento do Sistema de Avaliatividade, desdobrado na subseção 2.1, com foco principalmente no engajamento e nos recursos de expansão e contração realizados no sistema linguístico. Na seção 3 são apresentados os procedimentos metodológicos adotados para a análise. A seção 4 volta-se para a análise 
linguística com foco nos padrões de expansão e contração dialógicas de trechos do artigo da colunista Miriam Leitão. Por fim, na seção 5 são apresentadas as considerações finais.

\section{A Linguística Sistêmico-funcional e a Avaliatividade}

A LSF considera a língua como um complexo sistema semiótico de produção e troca de significados. Volta-se para o estudo da linguagem como um fenômeno social e cultural, em que os propósitos de interação estão diretamente relacionados com as escolhas linguísticas feitas pelos usuários em suas interações, dentre um potencial de possibilidades, para dar conta do que se pretende comunicar. Dessa forma, a língua é um aparato "funcional, semântico, contextual e semiótico" (EGGINS, 2004, p. 3) que utilizamos para construir significados no mundo.

De acordo com Halliday e Matthiessen (2014), a linguagem apresenta três funções básicas denominadas metafunções ${ }^{1}$, presentes em praticamente todos os atos comunicativos: a de construir experiências, a de negociar as relações sociais e a de organizar o fluxo de informação. A primeira metafunção, chamada de ideacional, é linguisticamente configurada para fornecer, por meio de recursos léxico-gramaticais, informações sobre a experiência humana. A segunda metafunção, a interpessoal, é mobilizada quando utilizamos a linguagem considerando as relações sociais e pessoais envolvidas. Essa metafunção está ligada à proposição de quem fala, ao informar ou questionar, ao dar uma ordem, ao avaliar ou expressar atitude com quem se fala. Por fim, a metafunção textual é responsável por mapear as sequências do discurso, relacionando-as ao contexto em que ocorrem e quais significados são negociados, além de organizar o fluxo discursivo.

Os pressupostos teóricos desenvolvidos por Martin e White (2005) baseiam-se nos sentidos interpessoais da linguagem que abordam aspectos subjetivos dos escritores ou falantes, à medida que se posicionam com quem se comunicam. O Sistema de Avaliatividade ${ }^{2}$ preocupa-se em analisar, na linguagem, como os falantes aprovam, desaprovam, entusiasmam, criticam, compartilham emoções, gostos, etc. (MARTIN; WHITE, 2005). Tal sistema abrange três recursos semânticos do discurso que constroem significados

\footnotetext{
${ }^{1}$ De acordo com Halliday e Matthiessen (2014, p. 31, tradução nossa), há uma escolha pelo termo metafunção em detrimento de função, pois "a análise sistêmica mostra que a funcionalidade é intrínseca à linguagem: isto é, toda a arquitetura da linguagem é organizada ao longo de linhas funcionais. A linguagem é como é por causa das funções em que se desenvolveu na espécie humana. O termo "metafunção" foi adotado para sugerir que a função era um componente integrante da teoria geral".

${ }^{2}$ De acordo com Vian Jr., Souza e Almeida (2010, p. 42), "as letras maiúsculas na GSF são usadas para referência ao plano do sistema, em oposição ao plano da atualização concreta (num texto, por exemplo) das possibilidades sistêmicas".
} 
interpessoais: atitude, engajamento e gradação. De acordo com os autores, o subsistema atitude abrange três campos semânticos: afeto, julgamento e apreciação. $\mathrm{O}$ afeto inclui os sentimentos e as reações emocionais; o julgamento volta-se para a construção linguística de comportamentos das pessoas e apreciação para os valores das coisas. O subsistema gradação apresenta dois campos semânticos: força e foco, e aborda, linguisticamente, os recursos da graduação dos sentimentos, o quão amplificado ou não (fraco ou forte) é um sentimento. $\mathrm{O}$ subsistema engajamento volta-se para as vozes do discurso e recorre a marcas de dialogia para convencer o leitor/ouvinte.

Este estudo preocupa-se com o subsistema de engajamento, buscando discutir/analisar os aspectos monoglóssicos e heteroglóssicos presentes em artigo de opinião. Assim, os conceitos mobilizados estão relacionados com esse subsistema, considerando também as subcategorias descritas a seguir que contribuirão para a análise.

\subsection{Engajamento: monoglossia e heteroglossia}

O engajamento constitui-se como um dos três subsistemas do Sistema de Avaliatividade propostos por Martin e White (2005), direcionado ao posicionamento e envolvimento da voz autoral com outras possíveis vozes e posições alternativas no contexto comunicativo (p. 94). Esse sistema toma por base as noções de dialogismo e heteroglossia de Bakhtin (1981), uma vez que a comunicação verbal, independente da forma, pretende "revelar a influência de, referir-se a, ou assumir de alguma forma o que foi dito/escrito antes, e simultaneamente para antecipar as respostas de leitores/ouvintes reais, potenciais ou imaginários"3 (MARTIN; WHITE, 2005, p. 92, tradução nossa).

Sendo assim, o subsistema de engajamento está relacionado com a perspectiva intersubjetiva da concepção dialógica de Bakhtin (1997), que pressupõe a natureza responsiva de qualquer enunciado, considerando que o falante/escritor não é o primeiro no mundo a se manifestar; antes dele outros enunciaram, portanto, todo aquele que enuncia é um respondente em maior ou menor grau em relação com outros enunciados anteriores e os que ainda virão. Significa que as manifestações discursivas estão relacionadas a outras que a antecederam e sugere uma atitude responsiva do ouvinte/leitor, ou seja, um texto, seja ele oral ou escrito,

\footnotetext{
${ }^{3}$ No original: “...reveal the influence of, refer to, or to take up in someway, what has been said/written before, and simultaneously to anticipate the responses o factual, potential or imagined readers/listeners" (MARTIN; WHITE, 2005, p. 92).
} 
está sempre em diálogo com outros textos, uma vez que "cada enunciado é um elo na corrente complexamente organizada de outros enunciados" (BAKHTIN, 1997, p. 272).

Com base nessa perspectiva dialógica, Martin e White (2005) atentam para a relação estabelecida entre falante/escritor com outros posicionamentos anteriores a respeito das mesmas questões e sobre a medida em que esses falantes/escritores reconhecem aqueles que vieram antes e como se relacionam com eles. Além disso, consideram o aspecto de antecipação responsiva pelos ouvintes/leitores, diante da proposição e da posição de valor presente no texto, se dada como certa ou se passível de questionamento, resistência ou rejeição.

O subsistema de engajamento apresenta recursos para que a voz autoral possa estabelecer o seu lugar, a sua posição nas interações, considerando não apenas o que se enuncia, mas também a forma como essa voz se coloca na interação em termos de atitudes na relação com outras vozes. Esses recursos de posicionamento intersubjetivo estão voltados para a função que falante/escritor desempenha na construção de significados e em como estabelece as relações de alinhamento e desalinhamento (concordância/discordância). Isso acontece diante das posições de valor em que os participantes da interação expressam suas crenças e suposições constituídas socialmente e, ainda, a relação com os supostos destinatários do texto. Além disso, a perspectiva dialógica de produção de significados desse subsistema permite que a voz autoral revele suas expectativas com relação a um possível leitor "imaginado" ou "ideal", chamado de leitor putativo. É com esse possível destinatário que o falante/escritor será considerado mais ou menos alinhado ou desalinhado, e às relações intersubjetivas estabelecidas entre esses interlocutores, os autores chamam de "solidariedade" (MARTIN; WHITE, 2005).

Na esteira do dialogismo bakhtiniano, Martin e White (2005) descrevem o subsistema de engajamento sob duas perspectivas: monoglossia e heteroglossia. A primeira caracteriza-se pela inexistência de espaço para outras vozes no discurso, pelo não reconhecimento de posições alternativas. Nesse caso, a proposição pode ser considerada dialogisticamente inerte, uma vez que o falante/escritor pode se manifestar de forma categórica. A segunda, ao contrário, está inserida num pano de fundo dialógico, que reconhece e se envolve com outras vozes no discurso e possibilita pontos de vista alternativos.

Com base nessas definições, os autores estabelecem uma subdivisão para a heteroglossia em duas grandes categorias, considerando se os recursos heteroglóssicos são “'dialogicamente expansivos' ou 'dialogicamente contrativos' em sua funcionalidade 
intersubjetiva"4 (MARTIN; WHITE, 2005, p. 102, tradução nossa). A expansão dialógica está relacionada com a possibilidade de alinhamento da voz autoral com vozes e posições alternativas. A contração dialógica restringe, desafia ou afasta a possibilidade de estabelecer relações com outras vozes textuais. Em outras palavras: a expansão dialógica abre espaço para o diálogo com outros textos, enquanto a contração dialógica o restringe (MARTIN; WHITE, 2005). Tanto a expansão quanto a contração dialógica são segmentadas em outras subcategorias, por meio das quais os significados intersubjetivos podem ser realizados.

A expansão dialógica se subdivide em entretenimento e atribuição. Por entretenimento entendem-se os enunciados através dos quais a voz autoral posiciona-se como sendo "uma de uma gama de posições possíveis" (MARTIN; WHITE, 2005, p. 98, tradução nossa), possibilitando a abertura dialógica para tais possibilidades, em menor ou maior grau. Diz-se, portanto, que o falante/escritor entretém as alternativas dialógicas. Essa abertura dialógica pode mobilizar significados através dos quais o falante/escritor faz avaliações de probabilidade por meio de auxiliares modais (pode, poderia, deve, etc.), de adjuntos modais (talvez, provavelmente, definitivamente, etc.), de atributos modais (é possível que..., é provável que... etc.), de circunstâncias (na minha opinião) e por meio de certas projeções mentais de verbo/atributo (eu suspeito que..., acho, acredito, estou convencido disso, duvido, etc.). A subcategoria de entretenimento apresenta também proposições baseadas em aparêncialevidência (isto parece, parece, aparentemente, a pesquisa sugere) e tipos de questões retóricas ou expositivas, que permitem avaliar uma proposição como sendo provável ou possível (MARTIN; WHITE, 2005).

A atribuição é a subcategoria em que se atribuem fontes externas à voz autoral do texto, que representa a proposição como uma de uma gama de posições possíveis. Tais proposições são fundamentadas na subjetividade dessa voz externa. Esse recurso pode ser expresso por meio de outras duas subcategorias: reconhecimento e distanciamento. $\mathrm{O}$ reconhecimento está relacionado às locuções em que não há indicação explícita do lugar da voz autoral, com relação à proposição, apesar de haver interação com a voz externa. Esse reconhecimento pode ser expresso por meio de processos verbais de relato, como dizer, relatar, declarar, anunciar, acreditar e pensar. O distanciamento tem a ver com um afastamento explícito da voz autoral em relação às vozes externas. Também pode ser representado por meio de processos verbais de relato, para reivindicar e/ou citar, contrastando

\footnotetext{
${ }^{4}$ No original: “... 'dialogically expansive' or 'dialogically contractive' in their intersubjective functionality" (MARTIN; WHITE, 2005, p. 102).

${ }^{5}$ No original: “... one of a range of possible positions" (MARTIN; WHITE, 2005, p. 98).
} 
com o reconhecimento no sentido de que a voz externa é identificada/localizada, como por exemplo: X afirma isso, há rumores de que (fulano), etc. (MARTIN; WHITE, 2005). A heteroglossia fica clara nos recursos de reconhecimento e distanciamento pela evidente referência da voz autoral à voz externa, no sentido de esquivar-se de tomar partido sobre as proposições.

A contração dialógica também apresenta outras duas subcategorias de significação: refutação e ratificação. A refutação se manifesta por meio de um posicionamento da voz autoral em desacordo ou rejeitando uma alternativa dialógica; os significados dessa subcategoria podem ser representados pela negação e pela contraexpectativa. A negação, dialogicamente, é um recurso que introduz uma posição alternativa positiva na interação comunicativa, reconhecendo-a para rejeitá-la. Isso quer dizer, em termos bakhtinianos, que toda negação supõe uma afirmação; a afirmação, no entanto, não necessariamente supõe a negação. Na contraexpectativa, como a própria palavra revela, a proposição formulada contraria o que seria esperado em seu lugar ao denotar oposição ou concessão a uma determinada ideia. Esse recurso é dialógico no sentido de que invoca uma posição contrária ao que seria o esperado e pode se manifestar por meio de expressões adversativas.

Por último, a ratificação compreende as formulações da voz autoral que pretendem contrapor ou anular diretamente uma posição contrária, no sentido de reiterar a confiabilidade da proposição. Três são as subcategorias de ratificação: confirmação de expectativa, pronunciamento e endosso. A confirmação de expectativa apresenta formulações que estão de acordo ou têm o mesmo conhecimento de uma voz externa e pode ser expressa, geralmente, por locuções tais como: claro, naturalmente, não surpreendentemente, reconhecidamente e certamente. O pronunciamento engloba formulações que revelam ênfase, intervenções ou interpolações autorais explícitas, no sentido de validar e conferir credibilidade a sua proposição. Podem ser expressas por meio de afirmações ou intensificadores como realmente, de fato, entre outros. O endosso tem a ver com as formulações em que a voz autoral considera como verdadeiras, corretas, válidas, inegáveis as proposições de fontes externas. Tais significados podem ser realizados por meio de processos verbais ou equivalentes nominalizados, que permitem à voz autoral pressupor garantia sobre a proposição. Dentre os processos verbais podem ser destacados como exemplos mostrar, provar, demonstrar, encontrar, apontar (MARTIN; WHITE, 2005).

Um esquema do subsistema de engajamento, abrangendo todas as suas categorias e subcategorias está representado na Figura 1 a seguir, adaptada de Bárbara e Ninin (2013, p. 131). As autoras basearam seu esquema em Martin e White (2005) e trazem como importante 
contribuição a ideia de que, dependendo das escolhas realizadas pelo escritor/falante, ele assume maior ou menor responsabilidade sobre o que expressa. Assim, enquanto na monoglossia o autor não abre espaço para questionamentos (a responsabilidade do que é proferido é máxima), na expansão dialógica as autoras apontam que há "adesão a outras vozes” (BÁRBARA; NININ, 2013, p. 13), sendo a responsabilidade mínima.

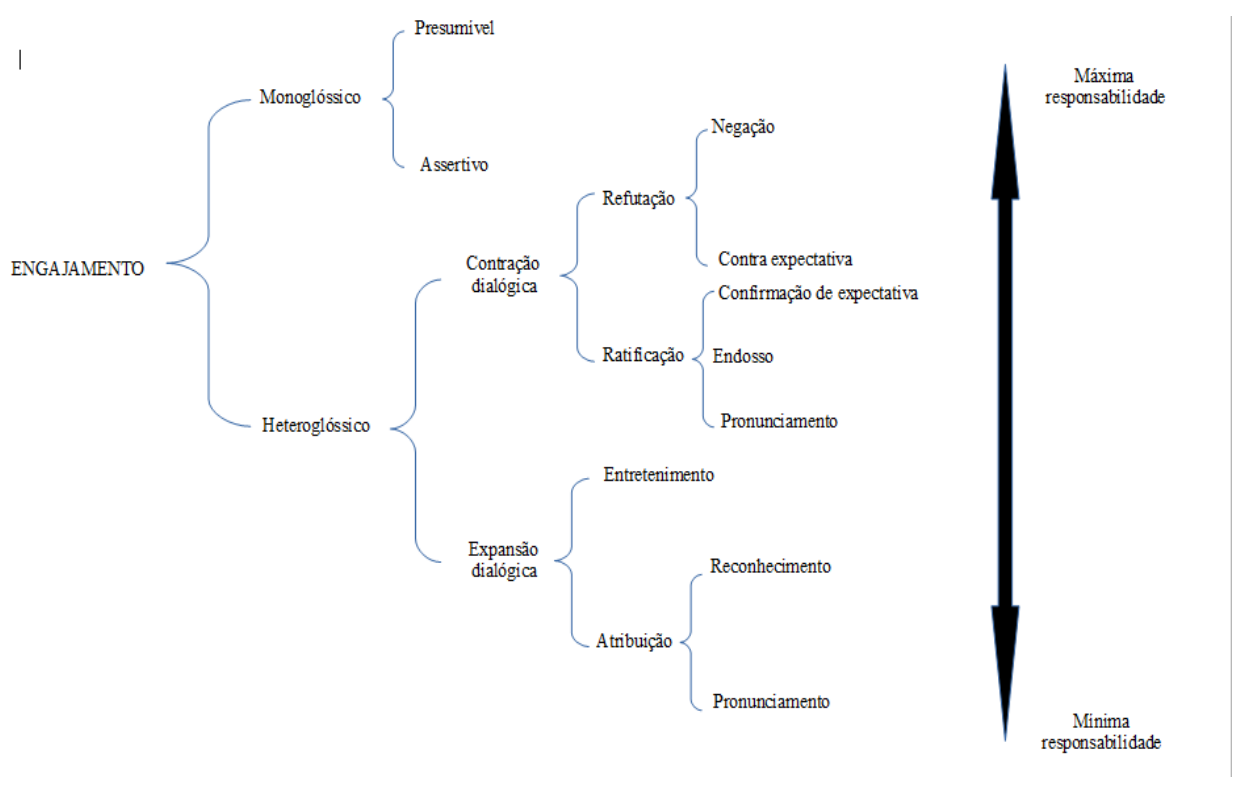

Figura 1 - Subsistema de engajamento

Fonte: adaptado a partir de Bárbara e Ninin (2013, p. 131)

A partir dessa breve explanação acerca do Sistema de Avaliatividade, mais especificamente do subsistema de engajamento, apresentamos a análise de um artigo de opinião, já mencionado anteriormente, com base nos procedimentos metodológicos definidos a seguir.

\section{Procedimentos metodológicos}

A proposta de análise deste artigo de opinião surgiu em contexto acadêmico de aprofundamento dos estudos acerca do Sistema de Avaliatividade da LSF. Por considerar que um texto jornalístico poderia contribuir para a compreensão dos aspectos referentes à monoglossia, à heteroglossia e, principalmente à forma como o escritor se relaciona com o público leitor, selecionamos um texto, publicado no jornal o Globo e escrito pela colunista Mirim Leitão, Impeachment pelo passado e futuro. Segue-se, então, uma análise de orações em que o engajamento ocorra, de forma que seja possível tecer conclusões sobre a relação 
estabelecida entre a autora e os seus leitores. Nesta análise, ancoramo-nos em Bárbara e Ninin (2013, p. 130, grifo nosso), quando esclarecem que "não é possível conhecer o envolvimento do autor com as proposições apresentadas no texto quando se analisa isoladamente as orações. É, pois, no conjunto delas, seja em um parágrafo ou enquanto durar um dado tema na trama textual, que se pode discutir a heteroglossia ou a monoglossia do texto".

Para tanto, como nos trazem Vian Jr., Souza e Almeida (2010), a análise de textos deve considerar como ocorrem as negociações entre escritor e leitor e como são construídos os significados interpessoais, qual atitude é esperada dos possíveis interlocutores, sejam eles explícitos ou não. Neste sentido, procurar marcas de alteridade e múltiplas vozes ou julgamentos únicos do autor passa por considerar que é necessário "um enfoque no direcionamento das vozes que se encontram no texto: de onde/quem partem e para onde/quem se dirigem e, mais importante que isso: quais vozes avaliam e quais são avaliadas" (VIAN JR.; SOUZA; ALMEIDA, 2010, p. 41).

Com relação ao público leitor do jornal O Globo em sua versão digital, a maioria pertence à classe B (59\%), com idade entre 20 a 39 anos (61\%), com escolaridade de nível médio (49\%), de acordo com dados do Infoglobo. O blog de Miriam Leitão, como é chamado o espaço em que seus textos são publicados digitalmente, volta-se para análises econômicas nacionais e internacionais em textos escritos pela autora, com acesso aos assinantes ou aos leitores cujos cadastros estejam ativos no sistema Globo. Referente ao perfil mais combativo de Leitão, Santos (2011, p. 19) coloca que, de acordo com o jornalista Reinaldo Azevedo, ela "não abria muito espaço para o contraditório. Havia sempre a sugestão nada leve de que os que se opunham à sua teoria gostavam mesmo era de farra, de inflação, de gastança" (SANTOS, 2011, p. 19).

Buscamos, assim, analisar o texto Impeachment pelo passado e futuro, produzido por Miriam Leitão em 24/01/2021, com o objetivo de examinar se há marcas predominantes de monoglossia, de forma que a jornalista coloque proposições textuais como certas, sem espaço de dúvida ao leitor, ou de heteroglossia, ou seja, se a autora traz outras vozes, afirmações anteriores ou antecipação de respostas para convencer o leitor do seu ponto de vista. Para essa análise, foram mobilizados os conceitos do subsistema de engajamento, monoglossia e heteroglossia, detalhados na seção 2 deste artigo, observando principalmente as subcategorias de contração e de expansão dialógica.

Num primeiro momento, realizamos uma análise do texto completo, parágrafo por parágrafo, buscando as ocorrências de engajamento para obter uma visão/avaliação do todo. Essa análise foi feita manualmente e o resultado aparece resumidamente na Figura 2. Depois 
disso, elegemos os dois últimos parágrafos para discutirmos e levantarmos hipóteses sobre cada ocorrência da análise realizada, primeiro, por considerar que são os parágrafos mais representativos do texto, ou seja, os que mais apresentam casos de engajamento. Segundo, por uma questão analítica e de limitação de espaço, não seria possível explicitar a análise do texto completo.

\section{Análise dos dados}

O texto Impeachment pelo passado e futuro, publicado na coluna de Miriam Leitão no jornal O Globo de 24/01/2021, apresenta a perspectiva da autora com relação à necessidade de abertura de um processo de impeachment contra o presidente Jair Bolsonaro. Assim, ao longo do texto, ela traz questões que, a seu ver, devem ser consideradas para a concretização do ato, assim como possíveis influências e posturas de diferentes instituições que poderiam influenciar na decisão.

A escritora também expõe, como pano de fundo da sua discussão, a tragédia ocorrida em Manaus em decorrência do descaso e do despreparo do governo federal durante a pandemia da Covid-19. Em janeiro do corrente ano, a imprensa brasileira noticiou que o Ministério da Saúde não enviou insumos aos pacientes internados em hospitais de Manaus. Inconformada com a situação, Leitão expõe, em seu texto, o caos ocorrido na saúde em virtude da falta de ações do presidente da república em relação à pandemia no Amazonas e cogita a possibilidade do seu impedimento.

A análise que segue abrange os 7 parágrafos do texto e desenrola-se conforme explicitado nos procedimentos metodológicos.

\begin{tabular}{|c|l|}
\hline 1 & $\begin{array}{l}\text { Dos argumentos contra o impeachment do presidente Jair Bolsonaro, o mais fraco é o de que não } \\
\text { podemos "banalizar" [contração: refutação: negação] esse instrumento. A lei é para ser usada }\end{array}$ \\
& [monoglossia], e em nenhum [contração: refutação: negação] outro caso anterior a este fez tanto \\
sentido iniciar o processo de punição que é previsto [contração: ratificação: endosso] na Constituição e \\
em lei de 1950 para o caso de o presidente cometer crime de responsabilidade. Bolsonaro incorreu em \\
vários crimes, inclusive comuns, desde que assumiu o cargo [monoglossia].
\end{tabular}

No parágrafo 1, Miriam Leitão privilegia a heteroglossia, convocando outras vozes para dialogar em seu texto, ao utilizar contrações. Também a monoglossia se faz presente em 2 ocorrências, ao afirmar que a lei é para ser usada, dando caráter de obrigatoriedade à obediência às leis. Ao fazer uma acusação-a de que o presidente incorreu em vários crimes - , a autora assume inteiramente para si a responsabilidade do que afirma, uma vez que 
compromete eticamente o presidente da nação.

\begin{tabular}{|c|l|}
\hline 2 & Não é a primeira vez [contração: refutação: negação] que escrevo isso neste espaço. Em maio do ano \\
passado escrevi que era necessário [expansão: entretenimento] não ter medo [contração: refutação: \\
negação] de encarar o impedimento, sempre traumático, mas agora necessário [contração: refutação: \\
contraexpectativa] para salvar vidas. Em outras colunas, listei [contração: ratificação: endosso] os \\
artigos das leis do país que ele tem ferido constantemente. No ano passado ele escalou nos ataques às \\
instituições justamente quando o Brasil começava o [expansão: entretenimento] enfrentamento a um \\
vírus mortal. É uma dupla perversidade [monoglossia].
\end{tabular}

No parágrafo 2, Miriam Leitão privilegia novamente a heteroglossia, abrindo o diálogo para o seu leitor, ao iniciar o parágrafo com uma negação e indicando que já havia escrito sobre o assunto em seu blog em outros momentos. A autora utiliza mais contrações (4 ocorrências), assumindo parcialmente a responsabilidade pelo que é afirmado. As ocorrências monoglóssicas aparecem na parte final do parágrafo, nos trechos em que a autora se refere ao presidente, o ano passado ele escalou nos ataques às instituições, e ao seu governo, é uma dupla perversidade.

\begin{tabular}{l|l}
3 & O impeachment da presidente Dilma não foi apenas [contração: refutação: negação] por um \\
preciosismo fiscal, por uma singela pedalada, como ficou na memória [contração: ratificação: endosso] \\
de muita gente, da mesma forma que Collor não foi abatido [contração: refutação: negação] por um \\
Fiat Elba. Com seus erros de decisão, sequenciais, Dilma desmontou a economia [monoglossia]. A \\
recessão destruiu 7\% do PIB em dois anos, a inflação voltou a dois dígitos, o desemprego escalou, o \\
déficit e a dívida deram um salto [monoglossia]. Tudo isso derrubou sua popularidade e ela não teve \\
[contração: refutação: negação] sustentação política. Não foi [contração: refutação: negação] um golpe. \\
Foi o uso do impeachment por crime de responsabilidade fiscal, e num contexto de descobertas de \\
assalto aos cofres da Petrobras para financiamento político [monoglossia].
\end{tabular}

O parágrafo 3 é marcado por 5 ocorrências de heteroglossia, sendo todas por contração. Isso remete, novamente, à análise de Bárbara e Ninin (2013), em que as autoras estabelecem que a contração dialógica estaria em uma escala média de responsabilidade. Ao iniciar o parágrafo colocando que o impeachment da presidente Dilma não foi apenas por um preciosismo fiscal, Leitão compreende que existem pessoas que não concordam com a sua assertiva, mas convida-as a dialogar com as suas ideias a partir de afirmações que remetem ao governo Collor. Na metade do parágrafo, a autora assume total responsabilidade ao ser monoglóssica, afirmando que Dilma desmontou a economia e trazendo dados sobre seu governo. A autora também se utiliza da conhecida expressão não foi um golpe e, ao utilizar-se da negação, novamente reconhece que há vozes divergentes da sua, mas avança em sua análise para lançar mão da monoglossia e finalizar o parágrafo afirmando que foi o uso do impeachment por crime de responsabilidade fiscal, e num contexto de descobertas de assalto aos cofres da Petrobras para financiamento político. 


\begin{tabular}{l|l|}
4 & Os crimes de Jair Bolsonaro estão em outro patamar de gravidade, [monoglossia] porque atentam \\
contra a vida [monoglossia]. A falta de coordenação federal da pandemia matou brasileiros \\
[monoglossia]. Ele estimulou o agravamento da pandemia por atos, palavras e omissões [monoglossia]. \\
Se permanecer intocado [expansão: entretenimento] e com o seu mandato até o fim, a história será \\
reescrita naturalmente [contração: ratificação: confirmação de expectativa]. O impeachment da \\
presidente Dilma parecerá injusto [expansão: entretenimento] e terá sido [expansão: entretenimento]. E \\
isso porque diante de crimes muito mais graves do que os que provocaram a desordem econômica, as \\
instituições cruzaram os braços e lavaram suas mãos deixando Bolsonaro protegido [monoglossia].
\end{tabular}

O parágrafo 4 inicia com várias assertivas monoglóssicas, em que a autora coloca de forma clara a sua opinião sobre o governo federal, e assume totalmente a responsabilidade sobre o que escreve. Nestes trechos, quando afirma que os crimes de Jair Bolsonaro estão em outro patamar de gravidade porque atentam contra a vida, [e que a] falta de coordenação federal da pandemia matou brasileiros, por exemplo, a autora estabelece pouca troca com o seu leitor, não abrindo o canal comunicativo para outras vozes possíveis. Ainda no mesmo parágrafo, Leitão volta a apresentar a heteroglossia em seu texto, com contração e expansões, mas finaliza o parágrafo de forma monoglóssica novamente ao afirmar que as instituições cruzaram os braços e lavaram suas mãos. Tal afirmação sobre a falta de atitude de tais instituições, mencionadas ao longo do texto, soa quase como uma acusação da autora e revela sua responsabilidade sobre o que escreve.

\begin{tabular}{l|l}
5 & O presidente faz seus movimentos ameaçadores diante de instituições inertes ou coniventes \\
[monoglossia]. A nota do procurador-geral da República, Augusto Aras, é inconcebível [monoglossia]. \\
Ele não apenas [contração: refutação: negação] diz [expansão: atribuição: reconhecimento] que não \\
fará [contração: refutação: negação] seu papel constitucional, como ameaça [expansão: atribuição: \\
reconhecimento] o país com uma insinuação de estado de defesa. Isso é a antessala de um golpe \\
[monoglossia]. Bolsonaro mais uma vez, nos últimos dias, usou as Forças Armadas para intimidar o \\
país [monoglossia]. E elas silenciam [monoglossia]. Ajudaram desde o início o presidente com seus \\
silêncios, suas palavras ambíguas, e sua presença ao lado de um ex-tenente que virou capitão quando \\
passou, com desonra, para a reserva [monoglossia].
\end{tabular}

O parágrafo 5 apresenta o mesmo recurso do parágrafo anterior, quando Leitão o inicia marcando a sua voz autoral e estabelecendo a sua posição monoglóssica, enunciando de forma pouco interativa com o seu leitor, não considerando outras vozes. Assim, a autora posiciona-se de forma contundente ao afirmar, por exemplo, que a nota do procurador-geral da República, Augusto Aras, é inconcebível. Embora o parágrafo apresente 4 ocorrências de heteroglossia, com duas ocorrências de contração e duas de expansão, o trecho é preponderantemente monoglóssico. 


\begin{tabular}{|c|l|}
\hline 6 & O Congresso é o próximo passo que está sendo dado pelo presidente. Ter políticos submissos na \\
presidência das duas Casas será a etapa final para a blindagem [monoglossia]. Bolsonaro avança nesse \\
propósito com a ajuda inclusive dos partidos de esquerda, como PT e PDT, que deram oficialmente seu \\
apoio a Rodrigo Pacheco (DEM-MG), o senador que diz serem “escusáveis" [expansão: atribuição: \\
distanciamento] os erros do governo. Que escusa existe para o caso de Manaus? [contração: \\
ratificação: confirmação de expectativa] Pessoas morreram sufocadas porque o governo não ouviu \\
[contração: refutação: negação] os alertas dos próprios funcionários do Ministério da Saúde, \\
[expansão: atribuição: reconhecimento] numa terrível cronologia da tragédia. O ministro lá esteve e \\
voltou prescrevendo [expansão: atribuição: distanciamento] tratamento que a ciência comprovou \\
[contração: ratificação: endosso] que é ineficaz [contração: refutação negação]. E o estado precisava de \\
oxigênio. [monoglossia]. Na Câmara também avança o candidato com o apoio do Planalto \\
[monoglossia].
\end{tabular}

O parágrafo 6 é caracterizado pela monoglossia, visto que a autora não coloca em discussão que o Congresso é o próximo passo que está sendo dado pelo presidente. Ter políticos submissos na presidência das duas Casas será a etapa final para a blindagem. Sua posição inicial é cristalizada, considerando que o leitor, da mesma forma, não cogitaria algo diferente, ou seja, estaria alinhado com o que é afirmado. Na sentença seguinte, a jornalista mobiliza uma voz externa, a do Senador Rodrigo Pacheco, que diz serem "escusáveis" os erros do governo. Ao utilizar o verbo dizer, ela expande por atribuição/distanciamento a existência de outras posições de valor alheia à sua própria. $\mathrm{O}$ uso de aspas em "escusáveis" revela um certo tom de crítica da autora e até de incredulidade diante da fala do senador, o que provoca um questionamento que pode ser considerado como um mote para a reflexão do leitor.

A pergunta retórica Que escusa existe para o caso de Manaus?, lançada ao leitor, presume que a resposta pode ser uma só: "Nenhuma". Assim, o texto opera no pressuposto de que o leitor concorda de forma previsível com a indagação. Neste sentido, há uma contração dialógica por ratificação/confirmação de expectativa, visto que exclui qualquer alternativa de dialogicidade. Logo em seguida, Miriam compromete-se ao refutar por negação em uma contração dialógica e posicionar-se contrariamente no trecho o governo não ouviu, ou seja, havia duas possibilidades: ouvir ou não, mas o governo preferiu não o fazer. Logo em seguida, na mesma frase, a jornalista expande por atribuição/reconhecimento ao dar voz aos funcionários do Ministério da Saúde: os alertas dos próprios funcionários do Ministério da Saúde. Novamente, ela mostra o seu posicionamento sobre a tragédia de Manaus por meio de outras vozes. A expansão dialógica também ocorre por atribuição/distanciamento no trecho $o$ ministro lá esteve e voltou prescrevendo tratamento, pois entendemos, nesta análise, que, ao utilizar o verbo prescrever (no sentido de dar uma ordem ou proferir para que o tratamento não comprovado seja feito), a autora distancia-se de forma explícita da proposição do 
Ministro, mostrando o seu posicionamento (de que o tratamento indicado pelo ministro é ineficaz).

Miriam contrai dialogicamente por ratificação/endosso a voz autoral para finalizar seu texto e construir a sua argumentação ao colocar que a ciência comprovou que é ineficaz e lança ao leitor uma fonte externa (ciência) para validar a sua voz de forma inegável. De forma complementar, ao escolher o verbo comprovar, é trazida a ideia de factividade, de algo indiscutível. De acordo com Martin e White (2005, p. 126, tradução nossa), "esse construto é mantido indiretamente pelo uso de processos verbais (ou seus equivalentes nominalizados) que retratam certos atos de semiose como fundamento para que o orador/escritor pressuponha garantia"6. Ao utilizar a palavra ineficaz, há uma contração dialógica por negação, ficando claro que a negação, neste trecho, é mobilizada para introduzir uma posição alternativa (eficaz), compartilhada com o seu leitor.

$\mathrm{Na}$ sequência, a autora assume total responsabilidade do que é dito ao afirmar monoglossicamente que o estado precisava de oxigênio. Por meio da monoglossia, ela introduz um ponto pacífico (da necessidade de oxigênio), não abrindo outras opções de negociação com o seu leitor. Espera-se que o leitor, sabendo da situação que ocorre em algumas cidades brasileiras, como Manaus, em que pacientes agonizavam em leitos à espera de oxigênio, concorde com a autora sobre a sua necessidade. Pode parecer contraditório mencionar monoglossia quando existem textos anteriores sobre os quais o autor pressupõe que o seu leitor saiba, mas como nos lembram Vian Jr., Souza e Almeida (2010):

[a]pesar de aparentemente incompatível com o posicionamento dialógico, a
monoglossia é considerada como uma opção estratégica do falante - negar o
dialogismo inerente ao processo comunicativo, adotando uma postura
sociossemiótica 'não dialogizada', a fim de tentar suprimir quaisquer enunciados
alternativos ou contraditórios. (VIAN JR.; SOUZA; ALMEIDA 2010, p. 60)

Leitão finaliza o parágrafo com Na câmara também avança o candidato com o apoio do Planalto, que se configura como uma assertiva monoglóssica, já introduzindo o tema do parágrafo seguinte.

O penúltimo parágrafo está composto na maior parte por heteroglossia, equilibrada entre expansão (três ocorrências) e contração dialógica (quatro ocorrências); enquanto a monoglossia está presente em menor número (duas ocorrências). As orações monoglóssicas revelam o firme posicionamento da autora com relação ao tema do texto e, mesmo as orações

\footnotetext{
${ }^{6}$ No original: "This construalis achieved in directly by the use of verbal processes (or their nominalised equivalents) which portray certain acts of semiosis as providing the grounds for the speaker/writer to presuppose this warrantability" (MARTIN; WHITE, 2005, p.126).
} 
heteroglóssicas não deixam margem para uma dialogicidade que possa interferir em suas ideias. A postura da voz autoral pode ser considerada, portanto, de alta responsabilidade, uma vez que assume fortemente as formulações ao longo do texto.

\begin{tabular}{l|l}
7 & Bolsonaro quer demonstrar [contração: ratificação: endosso] superioridade e que tudo está dominado. \\
Tem chances de colocar submissos nas presidências das duas Casas [monoglossia], a PGR já está em \\
suas mãos [monoglossia], as Forças Armadas aceitam ser o espantalho dos democratas [monoglossia]. \\
Muitos dizem [expansão: atribuição: reconhecimento] não ser estratégica [contração: refutação: \\
negação] a defesa do impeachment agora, porque ele seria barrado [expansão: entretenimento] pela \\
anomia das instituições. Isso não [contração: refutação: negação] é argumento [expansão: atribuição: \\
reconhecimento] para não defender [contração: refutação: negação] o impeachment do presidente \\
Bolsonaro. Ele cometeu inúmeros crimes [monoglossia] e precisa [expansão: entretenimento] \\
responder por eles. Se a democracia brasileira não [contração: refutação: negação] tiver forças para \\
tanto, ela mudará o passado. Serão injustos os impeachments anteriores [contração: ratificação: \\
pronunciamento]. O mais grave, contudo [contração: refutação: contraexpectativa], não [contração: \\
refutação: negação] é a mudança do passado, mas [contração: refutação: contraexpectativa] a do futuro. \\
Brasileiros estão morrendo hoje pela gestão criminosa da pandemia [monoglossia]. Em nome dos sem \\
futuro a democracia brasileira precisa [expansão: entretenimento] encarar o seu maior desafio.
\end{tabular}

No parágrafo que encerra o texto, na sentença Bolsonaro quer demonstrar, a autora contrai dialogicamente por ratificação endosso, pois traz presente a voz externa do presidente da república, por meio de uma locução verbal composta por um verbo desiderativo (quer) associado a um verbo de endosso, com o objetivo de demonstrar o anseio do presidente (demonstrar superioridade e que tudo está dominado). No entanto, ao escrever dessa forma, apesar de dar abertura a outra voz, a autora restringe o diálogo, dando a entender que o desejo de Bolsonaro não passa de uma tentativa não concreta. Ou seja, em certa medida, coloca em dúvida a veracidade do que a sentença revela.

$\mathrm{Na}$ sequência, aparecem três sentenças monoglóssicas, que não abrem espaço para o diálogo: Tem chances de colocar submissos nas presidências das duas Casas; a PGR já está em suas mãos; as Forças Armadas aceitam ser o espantalho dos democratas. Ao restringir a possibilidade de outras vozes neste trecho do texto, a autora se compromete fortemente com o seu posicionamento com relação às afirmações; em outras palavras, o discurso monoglóssico denota um alto comprometimento da autora.

Logo depois, Leitão expande dialogicamente na expressão Muitos dizem, neste caso por atribuição/reconhecimento, em que a heteroglossia fica evidenciada ao evocar eventuais textos produzidos anteriormente com relação ao tema e, que possivelmente dialogam com o que escreve a jornalista, mesmo que não esteja em concordância. Ainda, no mesmo complexo oracional, há uma contração dialógica por refutação/negação em não ser estratégica, em que a voz autoral assume total responsabilidade pela declaração, como no parágrafo anterior, trazendo vozes externas que revelam contrariedade em levar adiante um processo de 
impeachment neste momento, atribuindo o possível insucesso aos problemas de desorganização das instituições. Em seguida, há uma expansão por entretenimento em seria barrado, em que a autora abre espaço para outros posicionamentos, já que o seu é apenas um dentre uma série possível. Nesse caso, o auxiliar modal seria indica uma probabilidade no que se refere à discussão sobre o impedimento do presidente.

A contração por refutação/negação em Isso não e para não defender presente na sequência do texto, corrobora a postura da autora em favor de se levar adiante um processo de impeachment contra o presidente da República. Leitão assume seu posicionamento por meio da negação e, na sequência do texto, justifica seu pensamento. Ao expressar a necessidade de que Bolsonaro responda por seus crimes por meio de uma expansão dialógica/entretenimento em precisa responder por eles, a autora dá ênfase ao seu pensamento em relação a outras vozes que possivelmente não estejam de acordo. A heteroglossia está presente, portanto, mesmo que a voz autoral não abra espaço para a alternativa de diálogo.

Na sequência do texto seguem duas ocorrências de contração dialógica: uma por refutação/negação em não tiver forças, que denota uma possível consequência em não se dar atenção ao que a autora vem defendendo ao longo do texto, e outra por confirmação de expectativa/afirmação em ela mudará o passado que se confirma como sendo a consequência provável. Em contudo, a autora contrai dialogicamente por refutação/contraexpectativa, chamando a atenção para as possíveis consequências da falta de atitude em relação aos crimes cometidos pelo presidente. Depois disso, a voz autoral utiliza-se novamente do mesmo recurso de contração refutação/negação em não é a mudança do passado para introduzir uma outra consequência para o problema anteriormente mencionado, o que faz lançando mão do recurso de contração refutação/contraexpectativa em mas a do futuro.

Na sentença seguinte, Serão injustos os impeachments anteriores, a autora novamente utiliza o recurso dialógico de contração por ratificação/pronunciamento para enfatizar o seu pensamento acerca da possível situação que se desencadeará caso o processo de impeachment não seja concretizado. Seu texto dialoga com acontecimentos anteriores, os quais são de conhecimento geral da população, o que torna a sua afirmação relevante. De certa forma, convoca o público leitor a refletir sobre os acontecimentos e as motivações que os desencadearam, já que a sua afirmação de que o não impeachment de Bolsonaro tornará injustos os que já aconteceram significa que há motivações mais fortes ou plausíveis para o do atual presidente dos que o antecederam. Tal afirmação revela um comprometimento forte com o objetivo de convencer o leitor sobre a necessidade de se tomar uma posição frente aos desmandos e crimes cometidos por Bolsonaro. 
O desfecho do texto acontece com uma ocorrência monoglóssica em Brasileiros estão morrendo hoje, ressaltando não apenas a sua visão sobre os acontecimentos, mas de fato o que está ocorrendo no país. E, finalizando, a autora expande por entretenimento em $a$ democracia brasileira precisa encarar. Mais uma vez, por meio deste recurso heteroglóssico, a autora dá ênfase ao seu pensamento, às suas ideias no sentido de garantir sua validade em contraponto a outras vozes, geralmente contrárias.

Fica evidenciada, neste último parágrafo, uma postura heteroglóssica de Miriam Leitão que, utilizando-se de recursos tanto de expansão, como de contração dialógica, com a predominância desta, deixa clara sua posição referente ao tema do artigo, que é a defesa da abertura de um processo de impeachment contra o presidente Jair Bolsonaro, tendo em vista a negligência diante dos acontecimentos em Manaus. Isso foi possível, principalmente, pela utilização de subcategorias de engajamento que proporcionam a validação das ideias, revelando também uma alta responsabilidade de Miriam Leitão sobre o que ela escreve.

A seguir, apresentamos um quadro resumo de ocorrências do texto, na Figura 2.

\begin{tabular}{|c|c|c|c|c|c|c|c|c|c|c|c|c|}
\hline \multirow[b]{3}{*}{ 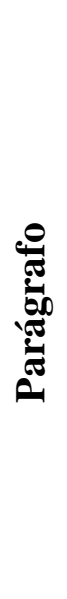 } & \multirow[b]{3}{*}{ 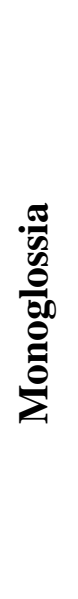 } & \multicolumn{9}{|c|}{ Heteroglossia } & \multirow{3}{*}{\multicolumn{2}{|c|}{ 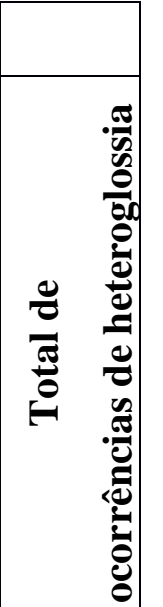 }} \\
\hline & & \multicolumn{6}{|c|}{ Contração } & \multicolumn{3}{|c|}{ Expansão } & & \\
\hline & & 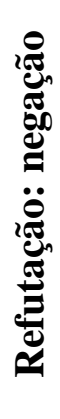 & 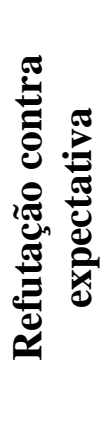 & 泀 & 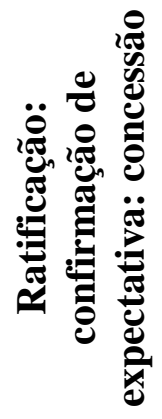 & 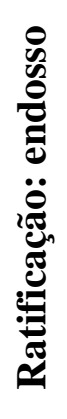 & 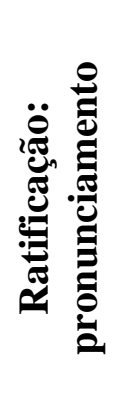 & 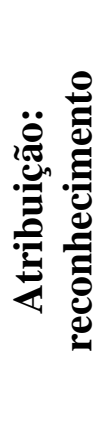 & 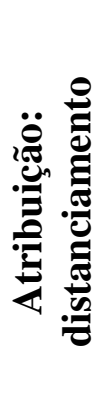 & : & & \\
\hline 1 & 2 & 2 & 0 & 0 & 0 & 1 & 0 & 0 & 0 & 0 & & 3 \\
\hline 2 & 2 & 2 & 0 & 1 & 0 & 1 & 0 & 0 & 0 & 2 & & 5 \\
\hline 3 & 3 & 4 & 0 & 0 & 0 & 1 & 0 & 0 & 0 & 0 & & 5 \\
\hline 4 & 5 & 0 & 0 & 1 & 0 & 0 & 0 & 0 & 0 & 2 & & 3 \\
\hline 5 & 6 & 2 & 0 & 0 & 0 & 0 & 0 & 2 & 0 & 0 & & 4 \\
\hline 6 & 3 & 2 & 0 & 1 & 0 & 1 & 0 & 2 & 1 & 0 & & 3 \\
\hline 7 & 4 & 5 & 2 & 0 & 0 & 1 & 1 & 2 & 0 & 2 & & \\
\hline
\end{tabular}

Figura 2: análise do texto "Impeachment pelo passado e futuro"

Fonte: Dados da pesquisa 


\section{Considerações finais}

O estudo aqui apresentado e fundamentado pela Linguística Sistêmico-Funcional de Halliday (1985; 1994) e Halliday e Matthiessen (2014), versou sobre os recursos de posicionamento intersubjetivo em texto midiático, com o olhar voltado principalmente para o Sistema de Avaliatividade da semântica do discurso (MARTIN; WHITE, 2005), enfocando o subsistema de engajamento. O objetivo foi reconhecer se a voz autoral presente no texto é monoglóssica ou heteroglóssica, no intuito de entender de que forma se constroem as relações entre a autora e o seu público leitor.

A análise dos parágrafos 1 a 5 revelou um aumento progressivo de ocorrências monoglóssicas: 2 no primeiro e no segundo, 3 no terceiro, 4 no quarto e 6 no quinto. Isso evidencia os momentos em que a autora não abre espaço para o contraditório em seu texto. Ainda que apresente ocorrências heteroglóssicas, sua posição segue um padrão de crescente responsabilidade pelo que é escrito, visto que as expansões se apresentam em menor número do que as contrações.

O parágrafo 6 revelou, por um lado, uma postura monoglóssica em 3 momentos, nos quais a autora não coloca em discussão o seu pensamento, não abrindo espaço para o diálogo com outras vozes. Revela uma posição cristalizada em possível alinhamento com o leitor. Por outro lado, a heteroglossia se faz presente no restante das sentenças, ora por expansão, ora por contração dialógica. O olhar da autora sobre o tema do artigo de opinião fica evidenciado nas sentenças contrativas, que, apesar de abrirem espaço ao diálogo com outras vozes, não possibilitam um diálogo efetivo com o seu pensamento. Mesmo nas sentenças em que ela expande dialogicamente, sua postura é muito firme com relação ao tema.

O último parágrafo apresenta 4 ocorrências monoglóssicas, tal como no parágrafo anterior, revelando máxima responsabilidade da autora sobre seu discurso. As sentenças heteroglóssicas, que sugerem a presença de outras vozes, são predominantes nesse parágrafo. São 13 ocorrências, dentre as quais, 9 por contração dialógica e 4 por expansão dialógica. Significa dizer que o texto de Miriam Leitão dialoga com outras possíveis vozes, sem deixar de afirmar e sustentar a sua própria ideia com relação ao tema do texto. Percebemos, pela forma como ela utiliza os recursos linguísticos, uma postura que assume inteiramente a responsabilidade sobre suas ideias e, principalmente, a tentativa de validar/confirmar o seu pensamento, com o intuito de, obviamente, convencer o leitor.

Dessa forma, em se tratando deste texto, consideramos que a voz autoral se apresenta como uma "onda monoglóssica", que aumenta progressivamente a partir do primeiro até o Organon, Porto Alegre, v. 36, n. 71, p. 71-90, jan./jun. 2021. 
quinto parágrafo, diminuindo nos parágrafos 6 e 7. Neste sentido, podemos considerar que a autora começa sendo mais heteroglóssica, abrindo um canal comunicativo mais abrangente com o seu leitor. Na metade da sua escrita, por outro lado, evidencia sua voz autoral com a responsabilidade máxima do que escreve, sendo majoritariamente monoglóssica, diminuindo, por fim, ao mobilizar mais recursos heteroglóssicos. Com relação ao número de ocorrências, pode-se afirmar que a autora foi majoritariamente heteroglóssica, primando por uma postura considerada como sendo de máxima responsabilidade, no sentido de que valida suas ideias sem deixar espaço para contraposição. O estudo deixa em aberto a possibilidade de novas análises para construir de forma mais consistente a avaliação acerca do posicionamento intersubjetivo da jornalista.

\section{REFERÊNCIAS}

BAKHTIN, M. M. Estética da criação verbal. 2, ed. São Paulo: Martins Fontes, 1997.

BAKHTIN, M. M. The dialogic imagination: four essays. Austin: University of Texas Press, 1981.

BARBARA, L.; NININ, M. O. G. Engajamento na perspectiva linguística sistêmico-funcional em trabalhos de conclusão de curso Letras. Trabalhos em Linguística Aplicada, Campinas, v. 52, n. 1, p. 127-146, jan./jun. 2013.

EGGINS, S. Introduction to systemic functional linguistics. London: A\&C Black, 2004.

HALLIDAY, M.A.K. An introduction to Functional Grammar. 2. ed. London: Edward Arnold, 1994.

HALLIDAY, M.A.K. An Introduction to Functional Grammar. London: Edward Arnold, 1985.

HALLIDAY, M.A.K.; MATTHIESSEN, C.M.I.M. An Introduction to Functional Grammar. 4. ed. London: Arnold, 2014.

INFOGLOBO. Nossos produtos. [Rio de Janeiro]: Infoglobo, 2009. Disponível em: https://www.infoglobo.com.br/Anuncie/ProdutosDetalhe.aspx?IdProduto=89. Acesso em $18 / 02 / 2021$.

LEITÃO, M. Impeachment pelo passado e futuro. Jornal O Globo, 24 jan. 2021. Disponível em: https://blogs.oglobo.globo.com/miriam-leitao/post/impeachment-pelo-passado-efuturo.html. Acesso em: 25 jan. 2021.

LISPECTOR, C. A descoberta do mundo. Rio de Janeiro: Nova Fronteira, 1984. 
MARTIN, J. R.; WHITE, P. R. R. The language of evaluation: appraisal in English. London: Palgrave, 2005.

SANTOS, A. de A. F. Miriam Leitão's blog and the language of economic journalism. 2011, 121 p. Dissertação (Mestrado em Comunicação) - Faculdade de Arquitetura, Artes e Comunicação, UNESP, Bauru, 2011.

VIAN JR., O.; SOUZA, A. A.; ALMEIDA, F. S. D. P. (Org). A linguagem da avaliação em língua portuguesa: estudos sistêmico-funcionais com base no Sistema de Avaliatividade. São Carlos: Pedro \& João Editores, 2010.

Artigo submetido em: 25 abr. 2021

Aceito para publicação em: 15 jun. 2021

DOI: http://dx.doi.org/10.22456/2238-8915.113364 